\title{
Ground Penetrating Radar investigation of limestone karst objects in the Botanical Garden in Kielce
}

\author{
Artur Zieliński ${ }^{1}$, Mikołaj Łyskowski², Ewelina Mazurkiewicz ${ }^{2}$ \\ ${ }^{1}$ Jan Kochanowski University in Kielce, Institute of Geography; ul. Świętokrzyska 15, \\ 25-406 Kielce, Poland; e-mail: aziel@ujk.edu.pl \\ ${ }^{2}$ AGH University of Science and Technology, Faculty of Geology, Geophysics and Environmental Protection; \\ al. A. Mickiewicza 30,30-059 Krakow, Poland; e-mail: lyskowski.m@gmail.com, ewemazurkiewicz@gmail.com
}

(C) 2016 Authors. This is an open access publication, which can be used, distributed and reproduced in any medium according to the Creative Commons CC-BY 4.0 License requiring that the original work has been properly cited.

Received: 28 January 2016; accepted: 30 March 2016

\begin{abstract}
Ground Penetrating Radar (GPR) is one of the most effective and rapid types of geophysical survey methods. The present study was carried out in the Botanical Garden in Kielce, which is currently undergoing a second stage of infrastructure development. This object is located in the Świętokrzyskie (Holy Cross) Region, characterized by large scale deformations in the development of karst origins. Those structures threaten existing buildings and can be obstacles to newly constructed ones. Radargrams presented in this paper show significant potential of the GPR method in mapping of karst phenomena. Proper acquisition parameters and optimal processing of raw data resulted in a clear image of the structure of rock mass under the Botanical Garden, along acquired profile lines. Additionally, precise GPS coordinate links and established researchers' experience of conducting this type of surveys helped in the process of mapping the anomalies in the limestone. Under these conditions, the survey minimized the need for a second method and resulted in high quality data acquisition. The study provided information about underlying rock mass structure development and registered anomalies whose origins include voids or caves of karst genesis. The area studied covers a large part of the Botanical Garden. Described anomalies can be dynamic in origin.
\end{abstract}

Keywords: GPR, karst, cave, Kielce, Botanical Garden

\section{INTRODUCTION}

With the development of geophysical measuring techniques, the possibility of their implementation is increasing. This is often observed in the case of the Ground Penetrating Radar (GPR) applications. Many communities such as archaeologists, geologists, architects and building investors recognise this method as a precise and fast survey type. Therefore, the presented study was proposed by the director of the modernized Botanical Garden in Kielce, with the purpose of mapping structural changes in the limestone rock mass under the facility area. After careful analysis of the literature and based on the authors experience (Eyskowski et al. 2014, Mazurkiewicz et al. 2015, Zieliński et al. 2016), it was decided that in this case, the GPR technique is the optimal method. Similar studies describing karst structures are presented by Beres et al. (2001). Published work consists of a comparison of GPR surveys with microgravimetric measurements. Very well documented results indicate that both methods complement each other when studying formations of karst origin. Chamberlain et al. (2000) applied a gird of parallel measuring profiles, thanks to which they received horizontal 
slices showing the placement of the cave system. The Świętokrzyskie (Holy Cross) Region is known for its dynamic karst origin phenomena (Urban 2007). Mazurkiewicz et al. (2015) used the GPR method for testing road foundations in areas with an increased risk of karst origin deformations. ElQuady et al. (2005) presented the results of the measurements in Egypt. The survey was carried out with use of the Electrical Resistivity Tomography (ERT) and GPR for precise cave mapping. The karst phenomenon is also dynamic in gypsum formation. Derobert \& Abraham (2000), and Łój et al. (2014) presented GPR results as an appropriate methodology not only for studying limestone origin karst. Doolittle \& Collins (1998) presented results from an electromagnetic induction method as compared to GPR. The purpose of the study was to detect and delaine major structural and solution features for improving site assessments. Given the above, the planned case study was supposed to verify whether there is a large-scale karst origin deformation in the structure of rock mass under the area of the modernized Botanical Garden in Kielce. The whole investigation was carried out without external funding and with the permission from the object's authorities.

\section{FIELD OF STUDY}

The specificity of the geological conditions in the Swiętokrzyskie Region is the presence of many objects of karst origin. Some of them may constitute certain risks for buildings and economic problems. Nevertheless, some of them like the Paradise Cave have become a major tourist attraction of regional value (Zieliński \& Janeczko 2016).

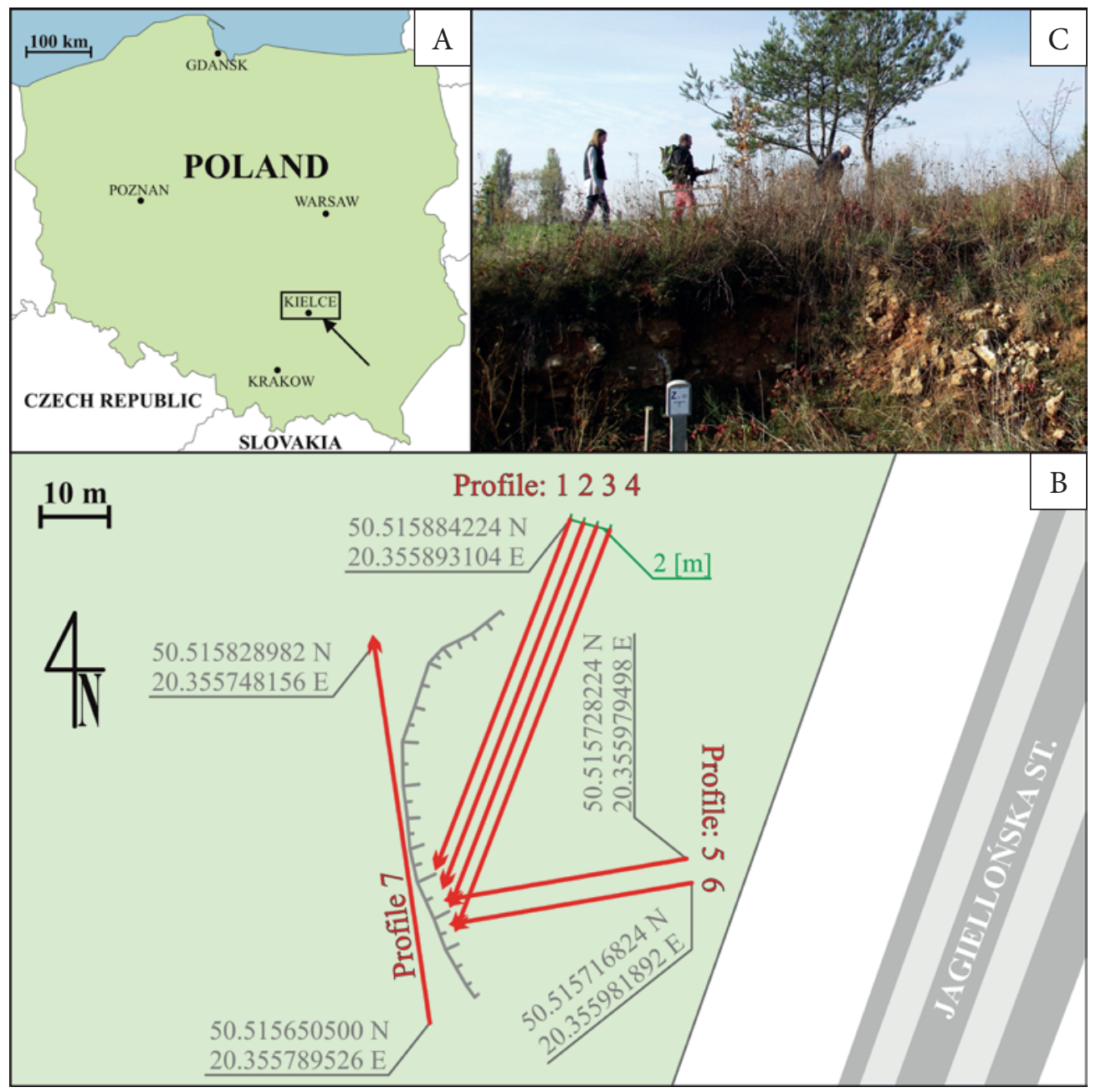

Fig. 1. Place of measurements located on the map of Poland (A). Schematic map of area where the GPR measurements were conducted. Coordinates were obtained from GPS Ashtech ProMark 800 (B). Photo taken during the measurements on GPR-profile 7 (C) 
In terms of geographical recognition, the city of Kielce is located in the Holy Cross Mountains in the area of the Silnica River (Kondracki 2013). As regards the geological setting, the city is located within the shaft of the Paleozoic Holy Cross Mountains in the Kielce Syncline. The area of Kielce is built of Middle Devonian and Lower Carboniferous limestones, which are covered by quaternary soils (Filonowicz 1973a, 1973b). Kielce city is the largest urban centre in the region, and yet in borders of the metropolis, the existence of very interesting geological reserves stands out as well as a host of various forms and objects of karst origin, including caves. Numerous karst objects are located here such as in the geological reserve Kadzielnia. Karczówka hill is also interesting. It is located in the western part of the city and is a part of the Pasmo Kadzielniańskie. The hill is also built of Devonian limestone. In the past, the hill was an important space for the development of ore mining in the city of Kielce. Then, industry of the region was based on lead sulfide (galena srebronośna). Karczówka was intensively exploited, which can be seen in numerous places of exploration and production. The most beautiful evidence of mining activity in this area is a unique sculpture of Saint Barbara made of solid galena. This figure is currently in the early Baroque chapel of the Church of Saint Karol Boromeusz at the Karczówka hill.

In this area, a large part of Karczówka Landscape Reserve is located in the Chęciny-Kielce Landscape Park and operates only in the regional Botanical Garden. It is located in the southeastern slope of the mountain Karczówka, in a crossing of Karczówkowska St. and Jagiellońska St. (Fig. 1B).

In the east, the lowest part near the Jagiellońska St., the garden architect designed small water reservoirs. The natural shape of the slope was anthropogenically transformed. Part of the slope was levelled by removing the Quaternary soils and even the most weathered limestone. In such a way, the precipitous slope with a height of $3 \mathrm{~m}$ was created (Fig. 1C). Below it, workers obtained a horizontal plane, where under the surface fractured limestone occurs (Śmiech 2005). Earthworks were completed in this part of the garden correcting any imbalances in the ground level. During this process, employees engaged in furnishing the garden discovered a local subsidence. The existence of such a form can be a consequence of the coexistence of large gaps, surface water drainage or even larger voids. For this reason, it was decided to carry out a GPR survey. Lack of a good geological documentation in this area was another argument, because inaccurate recognition may lead to various problems in the future.

\section{STUDY METHOD}

Today's Ground Penetrating Radar system includes several elements such as: a central processing unit, a signal generator, a transmitter, transmitting and receiving antennas, a receiver and a revolving mechanism. To control, facilitate data acquisition and pre-process in the field part of the GPR system a laptop is used (Reynolds 1997). The modern system mainly uses the bistatic type of antennas, where one of them serves as a transmitter and the other as a receiver (Annan 2001). Mala GeoScience, the Swedish manufacturer, offers antennas with frequencies ranging from $25 \mathrm{MHz}$ to $2300 \mathrm{MHz}$. The choice of the value of frequency depends on the size of the searched object, and depth which is expected. Based on the structure, bistatic antennas can be divided into two most commonly used types: shielded and unshielded. The advantage of shielded ones is their housing, which makes them less prone to external interference, such as reflections from trees, and the fact that they are designed for aiming the Electromagnetic (EM) wave directly into the medium.

The principle of the GPR survey is the generation of a pulse of radio waves at a frequency determined by the characteristics of the antennas. EM waves are emitted from a source to detect an object at a distance and determine the direction to the object. The system measures the distance to the object, but expresses it in two-way travel time value. The most important fact is the reflection of radio waves form an object, which has to have different dielectric properties from the surrounding host material (Annan 2001). Emitted radio waves travel at a speed that depends on the material in which they propagate. The electromagnetic characteristics of materials are related to their composition and water saturation. High frequency radio waves used in the GPR system make them sensitive to both changes in conductivity and dielectric properties of the materials. This affects the speed of radio wave propagation and the attenuation 
of electromagnetic waves in the medium (Reynolds 1997).

The depth range of the GPR method is determined primarily by the coefficient of wave attenuation. This parameter means a gradual reduction of the electromagnetic pulse amplitude along the travel path. It depends on four basic factors. First, is a geometrical divergence of the wave front, which corresponds to the point source of the wave. Second, a scattering related to non-homogeneity of the medium. Third, propagation dispersion of the waves, which depends on their frequency. Finally, electrical conductivity of the medium, which usually corresponds to fluids in pores (Annan 2001). The coefficient of wave attenuation is directly connected to the frequency of the signal emitted by the antennas. Those facts lead to the conclusion that the lower the frequency of emitted EM wave, the greater the depth penetration range, but the lower the resolution of the survey. The resolution can be divided into vertical and horizontal parameters. The simplest definition of both says that it is the minimum distance between two objects with the same cross section that are visible on the echogram as separate anomalies (Annan 2001).

One of the aims of the GPR survey is to determine the depth range of the anomalies seen on radargrams. For the purpose of obtaining the depth axis, it is necessary to do a time-depth conversion. This process requires acquiring the value of EM wave velocity in the medium, which can be obtained from WARR profiling (Wide-Angle Reflection and Refraction). Another method is the calculation of the velocity value from the relative dielectric constant in published data (e.g. Reynolds 1997; OYO 1988). The calculated wave propagation velocity is given as the quotient of the EM wave propagation velocity in vacuum $(c=0.3 \mathrm{~m} / \mathrm{ns})$ and the square root of the relative permittivity of the studied medium $v=\frac{0.3}{\sqrt{\varepsilon_{r}}}$. The end result of the GPR measurements is a collection of the traces on which a two-way travel time of EM wave propagation and its amplitude are recorded - the radargram. Traces register the electromagnetic wave amplitudes in the function of time. They are arranged one by one along the $\mathrm{X}$-axis. The length of the profile is calculated by the computer by a revolving mechanism. This equipment can slip during the time of measurement, therefore some inaccuracy in determining the profile length can be observed.

\section{RESULTS}

The results presented in this paper were obtained using a ProEx GPR unit (MalaGeoscience Sweden), with a $100 \mathrm{MHz}$ unshielded antenna. This combination allowed the acquisition of information to a depth range of about $12 \mathrm{~m}$. The whole case study consisted of 7 GPR-profiles conducted in classical reflection profiling. Their location and direction is presented on a schematic map of the survey site (Fig. 1B). Used acquisition parameters were set to: samples count -610 , time window $-\sim 630 \mathrm{~ns}$, stacks -8 , distance interval for EM wave recording $-0.05 \mathrm{~m}$. As supplement work, the authors used an unshielded $200 \mathrm{MHz}$ antenna. This survey was conducted on profile lines from the $100 \mathrm{MHz}$ antenna in places where, during the measurement, anomalies appeared. Additional profiles were also carried out. The obtained results from this survey did not bring about any additional information, and authors omitted them in this paper.

To interpret the date, the authors adopted a velocity value at the level of $0.12 \mathrm{~m} / \mathrm{ns}$. The literature study confirmed that this parameter is properly chosen. The tabular velocity value for limestone ranks in the range from $0.09 \mathrm{~m} / \mathrm{ns}$ to $0.15 \mathrm{~m} / \mathrm{ns}$ (OYO 1988, Annan 2001, Reynolds 1997). Recognising the margin of error at the level of $0.01 \mathrm{~m} / \mathrm{ns}$, after time-depth conversion, the depth Y-axis can generate misinterpretation at a level of about $0.5 \mathrm{~m}$. The authors would also like to mention that the conversion process averages the scale and makes the medium somehow like it was homogeneous. This situation in nature is almost not possible to encounter.

For interpretation and presentation purposes, radargrams were processed. Simple mathematical functions were used in a form of filters available in a specialized program ReflexW (Sandmeier software). The main aim of the processing is to improve the signal-to-noise ratio. The used procedures intended to e.g. the shift of first breaks, picking to the level zero, removing noise by frequency filters, enhancement of the amplitude value by gain functions, or smoothening the image in order to eliminate the temporary distortions of the signal (ReflexW Manual 2009). It is important to note that the interference in the raw data should be as small as possible. Too extensive or incorrect processing may result in e.g. generating artificial anomalies on the radargram. 


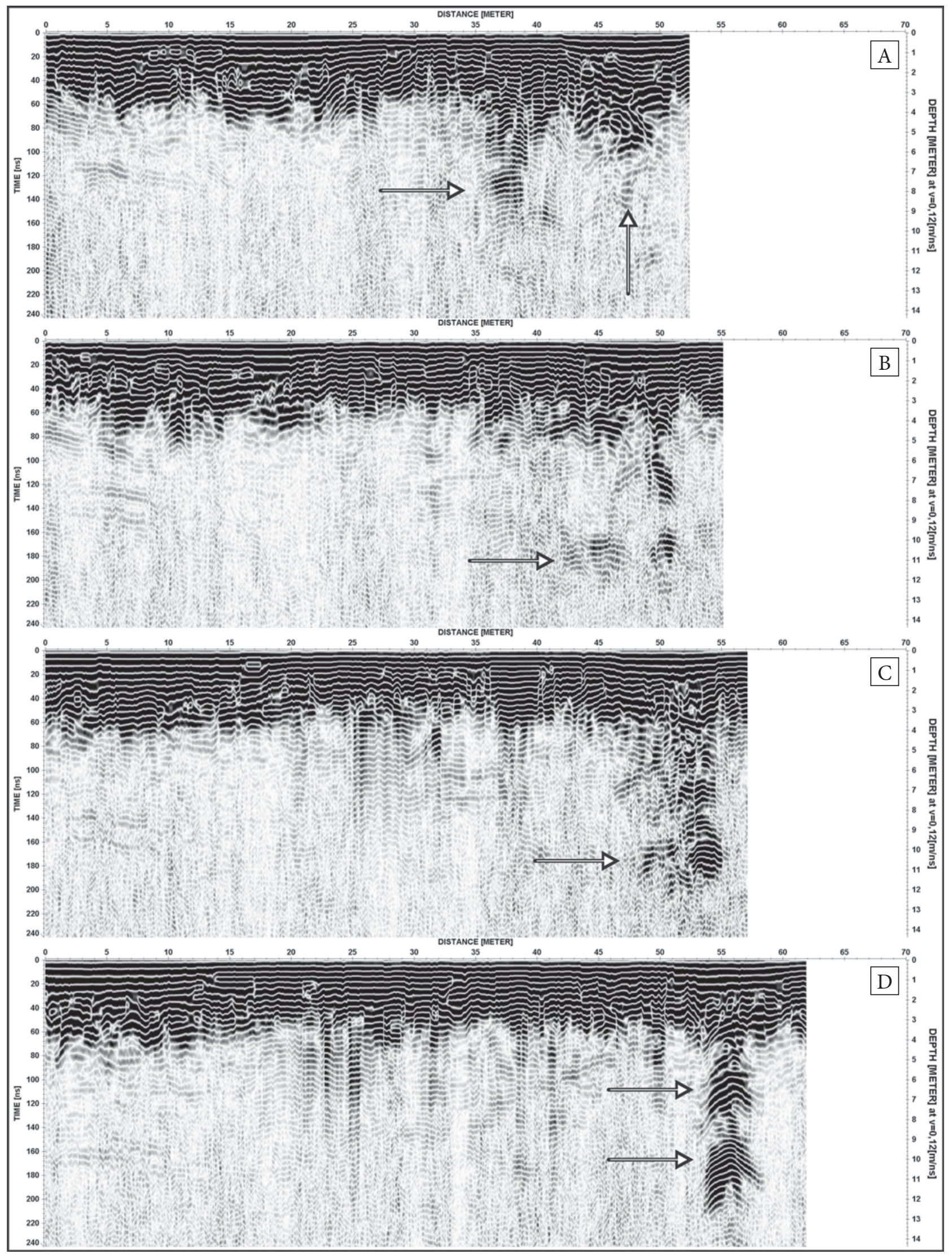

Fig. 2. Radargrams from GPR-profiles 1 (A) to 4 (D) made with the use of the $100 \mathrm{MHz}$ unshielded antenna (arrows indicate a karst origin structure) 
Parallel GPR-profiles 1 to 4 (Fig. 2) indicate the existence of a large structure, probably of karst origin, reaching a size of at least $6 \mathrm{~m} \times 8 \mathrm{~m}$, and depth range up to $12 \mathrm{~m}$ below the surface. On radargram no. 1 (Fig. 2A), it can be observed from about 35-49 $\mathrm{m}$. After analysis of the rest of the profiles, only the part between 43-49 m, at a depth of 4-6 m, can be recognized as continuous. GPR-profile no. 2 (Fig. 2B) presents readable anomalies, between
35-52 $\mathrm{m}$, at a depth of 6-12 $\mathrm{m}$. Those changes on the radargram prove the existence of a structure of karst genesis. On the radargram no. 3 (Fig. 2C), the structure is more clearly visible between $47-56 \mathrm{~m}$. Its vertical range can be determined between 2-12 m deep. GPR-profile no. 4 (Fig. 2D) shows the anomaly between $53-58 \mathrm{~m}$, and in this case, it can be divided into two groups of reflections: at a depth of $6 \mathrm{~m}$ and $10 \mathrm{~m}$.

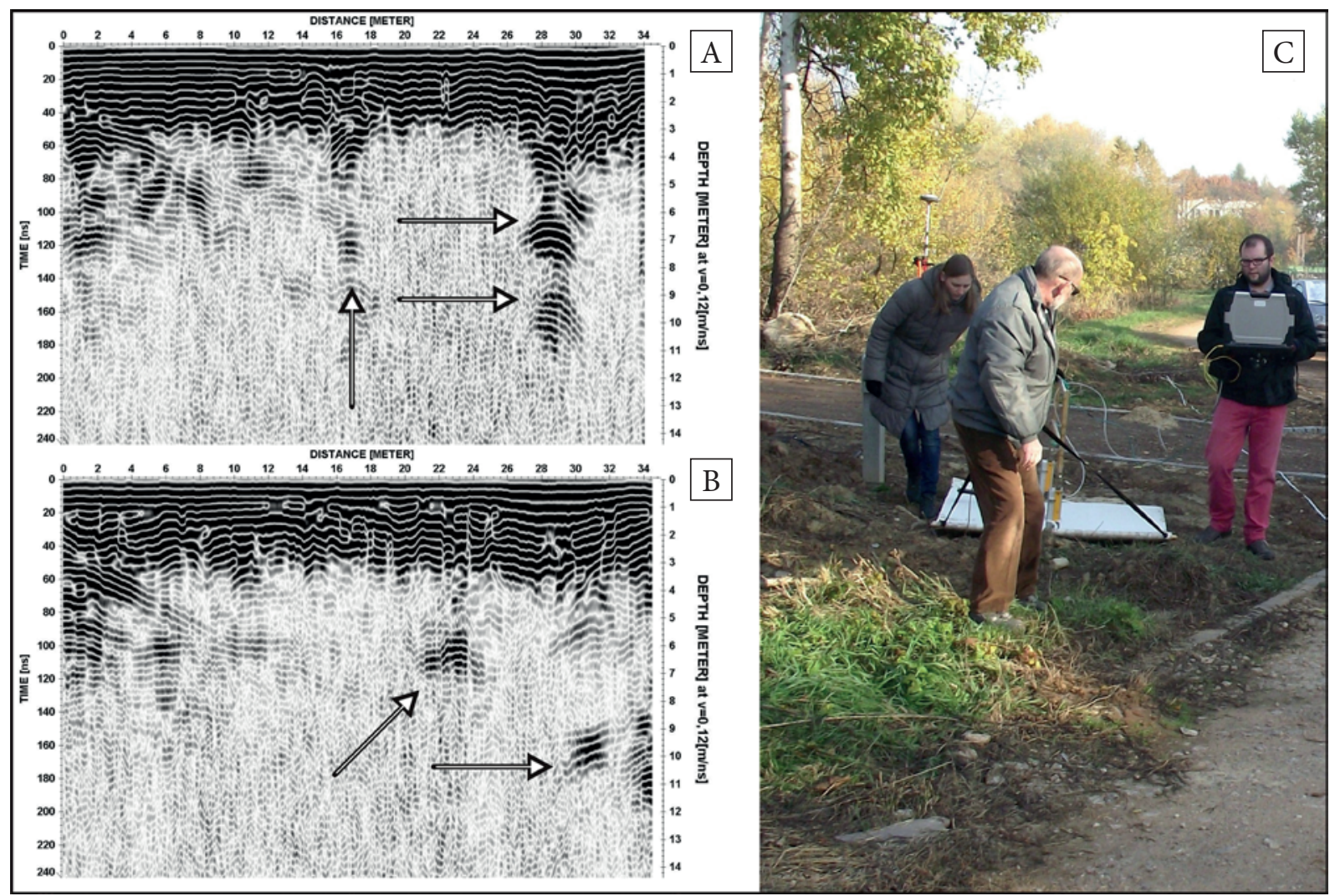

Fig. 3. Radargrams from GPR-profiles 5 (A) and 6 (B) made with the use of $100 \mathrm{MHz}$ unshielded antenna (arrows indicate a karst origin structure). Photo taken during adjustment of the acquisition parameters (C)

The anomalies recorded on radargrams no. 5 and 6 (Fig. 3) confirm the existence of the previously indicated structure. GPR-profile 6 (Fig. 3B) additionally presents a small change between 21-25 $\mathrm{m}$ at a depth of about $6 \mathrm{~m}$, and vertical range about $1 \mathrm{~m}$. Anomalies visible on both profiles up to $10 \mathrm{~m}$ probably originate from the structure inside the rock, though they are masked by reflections from objects on the ground surface. On radargram no. 7 (Fig. 4), between $14-18 \mathrm{~m}$, at a depth of about $10 \mathrm{~m}$, a small change is visible in the image. Its vertical range reaches about $4 \mathrm{~m}$. It can be directly linked to the structures shown on the GPR-profiles from 1 to 6 , but due to a higher level of ground of about $2 \mathrm{~m}$, the change on the radargram can be seen at greater depth. 


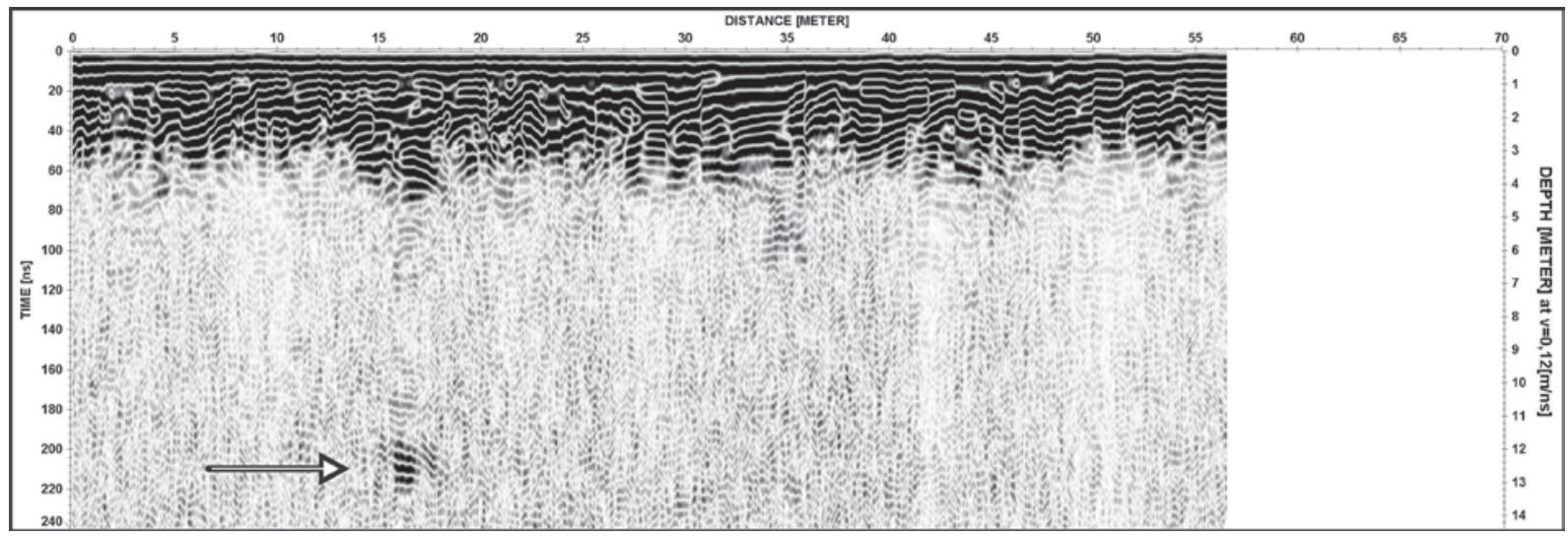

Fig. 4. Radargram from GPR-profile 7 made with the use of $100 \mathrm{MHz}$ unshielded antenna (arrows indicate a karst origin structure)

\section{DISCUSSION}

The results obtained in this survey have high resolution and clarity of the images on the radargrams, and show that conducted measurements are satisfactory and precise. Mapped anomalies from karst origin structures are visible and large in scale. Predicted size of the discovered structure can be estimated at level of at least $8 \mathrm{~m} \times 10 \mathrm{~m}$. The vertical extent of the zone of structure deformation reaches up to $7 \mathrm{~m}$ (to about $12 \mathrm{~m}$ deep under the ground level).

Limitations of the GPR method cannot be omitted. Several problems with conducting measurements and their interpretation should be discussed. The survey has considerable space requirements. For carrying out the GPR measurements, antennas need direct contact with the ground surface. The depth penetration range and resolution is connected directly to this limitation. With greater depth penetration, range size and antenna weight increases, e.g. unshielded $100 \mathrm{MHz}$ antenna measures $1 \mathrm{~m} \times 1 \mathrm{~m}$, and weights about $2.2 \mathrm{~kg}$ plus the weight of the frame and antenna electronics with batteries. The obtained $13 \mathrm{~m}$ depth penetration range at this survey showed that the choice was proper. Unfortunately, if the karst structures were deeper, there would be a necessity to use approximately a two times bigger $50 \mathrm{MHz}$ unshielded antenna. However, with use of the low frequency antenna, it is necessary to analyse if the lower resolution would be enough to map rock structures and deformations in it. In this case for the almost ideal bedrock for the GPR measurements (dry limestone covered with anthropogenic ground), the $100 \mathrm{MHz}$ antenna gave good quality and high resolution data proving that this frequency is the optimal choice. Additionally, disadvantages connected with unshielded types like reflections from the objects above the ground level were not registered on radargrams.

For the purposes of a full inventory of the cave, it is necessary to perform a comprehensive study with the use of other geophysical methods. Unfortunately, the authors do not have access to other geophysical equipment. However, a precise GPS coordinate link, experience with conducting this type of survey, thought-out profile lines, good acquisition parameters and optimal processing of raw data, minimized the impact of the lack of a second method and resulted in high quality data. Despite the use of only one geophysical method, information about karst structure development gave a more comprehensive picture of rock mass in the area of the emerging Botanical Garden. Other methods such as the microgravity (Beres et al. 2001) complementary method would give more precise data about the size of the karst structure. As a disadvantage to be mentioned, this method is much more expensive and time-consuming.

\section{CONCLUSIONS}

Authors obtained high quality results with a high resolution of measurement. By using a GPS device, the location of measurements has been precisely identified. The surveyed area was characterized by the existence of small size trees. It was covered mainly by medium high bushes. For this 
reason, the choice of the unshielded antenna was proper. The authors expected that the propagating in the air EM wave will not have many objects from which it could reflect, and, as a result, register them as anomalies on the radargrams. The resulting images show that the appropriate measurement methodology was used, in spite of indifferent site weather and terrain conditions. The registered and described anomalies come mainly from the structures of the objects of karst genesis. Due to the lack of the precise value of velocity and borehole data, the size of the object can be misinterpreted in scale of about $\pm 1 \mathrm{~m}$ in vertical size. The horizontal diameter can be only estimated. Only a precise and large scale grid could produce accurate data, but terrain condition made it impossible to create one. As for the anomaly area, it covers a large part of the emerging Botanical Garden and can be dynamic in origin. The authors suggest that it is necessary to conduct research on a bigger scale for the purpose of mapping the karst genesis structures on the whole terrain. Otherwise, the risk of further development and damage for planned objects on the ground will increase.

The authors would like to express gratitude to our colleagues from the AGH University of Science and Technology - Jerzy Ziętek, Ph.D., who is an invaluable mentor and Anna Strzepowicz, M.Sc., who helped with field measurements and to Janusz Łuszczyński, Ass. Prof. of UJK for inspiring us with the problems of karst in the Kielce Botanical Garden. The authors also thank Eliżbieta Czajkows$k a, M . S c$. for making the research possible, Joanna Jaśkowska, M.A. and Katarzyna Socha, M.Sc. for their help. The authors would like to thank the Reviewers for suggestions, which allowed us to improve the manuscript.

\section{REFERENCES}

Annan A.P., 2001. Ground Penetrating Radar Workshop Notes. Sensors \& Software, Ontario - Canada.

Beres M., Luetscher M. \& Olivier R., 2001. Integration of ground-penetrating radar and microgravimetric methods to map shallow caves. Journal of Applied Geophysics, 46, 249-262.
Chamberlain A.T., Sellers W., Proctor C. \& Coard R., 2000. Cave Detection in Limestone using Ground Penetrating Radar. Journal of Archaeological Science, 27, 957-964.

Derobert X. \& Abraham O., 2000. GPR and seismic imaging in a gypsum quarry. Journal of Applied Geophysics, $45,157-169$.

Doolittle J.A. \& Collins M.E., 1998. A comparison of EM induction and GPR methods in areas of karst. Geoderma, $85,83-102$.

El-Quady G., Hafez M., Abdalla M. A. \& Ushijima K., 2005. Imaging subsurface cavities using geoelectric tomography and ground-penetrating radar. Journal of Cave and Karst Studies, 67, 3, 174-181.

Filonowicz P., 1973a. Objaśnienia do Szczegółowej mapy geologicznej Polski 1:50 000. 815, Arkusz Kielce. Wydawnictwa Geologiczne, Warszawa.

Filonowicz P., 1973b. Szczegółowa mapa geologiczna Polski 1:50 000. 815, Arkusz Kielce. Wydawnictwa Geologiczne, Warszawa.

Kondracki J., 2013. Geografia regionalna Polski. Warszawa, PWN.

Łój M., Gołębiowski T. \& Porzucek S., 2014. Geophysical surveys and modelling for recognizing of gypsum karst. Geoinformatica Polonica, 13, 1, 83-97.

Łyskowski M., Mazurek E. \& Ziętek J., 2014. Ground Penerating Radar investigation of limestone karst at the Odstrzelona Cave in Kowala, Świętokrzyskie Moutains, Poland. Journal of Cave and Karst Studies, 76, 3, 184-190.

Mazurkiewicz E., Łyskowski M. \& Strzępowicz A., 2015. Aplikacja metody GPR do badania dróg na terenach o zwiększonym zagrożeniu deformacjami o genezie krasowej. Logistyka, 4 [CD nr 3 Logistyka - nauka], 9474-9479.

OYO, 1988. OYO Georadar I Manual. OYO Corporation, Tsukuba, Japan.

ReflexW Manual, 2009. User Guide. SandmeierGeo. Karlsruhe, Germany.

Reynolds J.M., 1997. An Introduction to Applied and Environmental Geophysics. John Wiley \& Sons, England.

Urban J., 2007. Permian to Triassic paleokarst of the Świętokrzyskie (Holy Cross) MTS, Central Poland. Geologia, $33,1,5-50$.

Śmiech S., 2005. Dokumentacja geotechniczna warunków geologicznych i hydrogeologicznych dla potrzeb zagospodarowania Ogrodu Botanicznego w Kielcach, ul. Bernardyńska, Karczówkowska, Jagiellońska w Kielcach. Przedsiębiorstwo Usług Geologicznych „Kielkard” [unpublished].

Zieliński A. \& Janeczko K., 2016. Największe atrakcje turystyczne w województwie świętokrzyskim w opinii turystów. Zeszyty Naukowe - Uniwersytet Szczeciński, Ekonomiczne Problemy Turystyki, 2, 34, 297-307.

Zieliński A., Mazurkiewicz E. \& Łyskowski M., 2016. GPR mapping of karst formations under a historic building in Szydłów, Poland. Geofizika [accepted on February 5 2016 for print in the June 2016 issue]. DOI: 10.15233/ gfz.2016.33.4. 